\title{
Study on the influence of reactive power regulation to the power grid in the pumped storage power station
}

\author{
Qu Ying ${ }^{1, a}$, Lei $\mathrm{Da}^{1, \mathrm{~b}}$, Xue Min ${ }^{1, \mathrm{c}}$, Zheng Huiping $^{1, \mathrm{~d}}$, Hao Xinjie $\mathrm{H}^{1, \mathrm{e}}$ \\ ${ }^{1}$ State Grid Shanxi Electric Power Research Institute, Taiyuan 030001, China

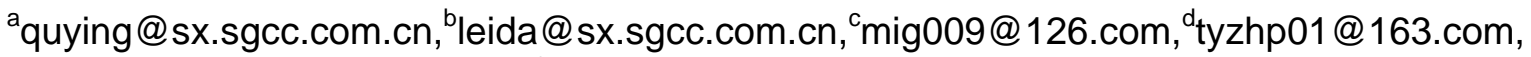 \\ ehaoxinjie@sx.sgcc.com.cn
}

Keywords: reactive power, pumped storage, influence

\begin{abstract}
The voltage of power grid will drop when the units pump water in the pumped storage power station.This paper uses the method of simulation and field test to study effect of reactive power regulation on the power grid in the pumped storage power station,which will provide reference for voltage regulation of pumped storage units and meet the peak load regulation of power grid and acceptance of wind power requirements.
\end{abstract}

\section{Introduction}

With capacity of wind power increasing, the units in pumped storage power station is required to operate under the pumping condition in order to improve ability of the peak load regulation of power grid and accept more clean energy, which will cause the bus voltage of power station too low to meet the operation requirement of power grid.Therefore, it is urgent to study effect of reactive power regulation on the power grid in the pumped storage power station in order to meet the peak load regulation of power grid and acceptance of wind power requirements.

\section{Brief introduction to the the operation principle of pumped storage units}

As a kind of synchronous motor, the pumped storage units can be operated under the condition of generator and motor. The vector diagram of the pumped storage unit is shown in fig.1.

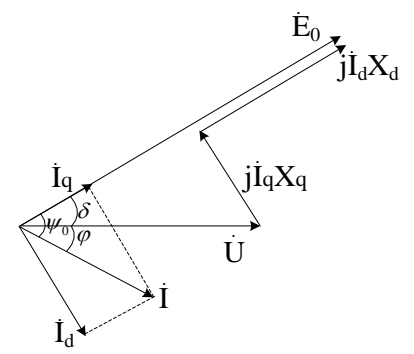

Fig.1 The vector diagram of the pumped storage unit

When the armature resistance is neglected, the electromagnetic power of the pumped storage unit is:

$$
P_{e} \approx m U I \cos \varphi
$$

The following formulas can be deduced form the vector diagram of fig.1:

$$
\begin{aligned}
& \varphi=\psi_{0}-\delta \\
& P_{e} \approx m U I \cos \varphi \\
& =m U I\left(\cos \psi_{0} \cos \delta+\sin \psi_{0} \sin \delta\right) \\
& =m U\left(I_{q} \cos \delta+I_{d} \sin \delta\right) \\
& I_{q} X_{q}=U \sin \delta
\end{aligned}
$$




$$
I_{d} X_{d}=E_{0}-U \cos \delta
$$

According to the above formulas, it can be deduced that:

$$
P_{e}=m \frac{E_{0} U}{X_{d}} \sin \delta+m \frac{U^{2}}{2}\left(\frac{1}{X_{q}}-\frac{1}{X_{d}}\right) \sin 2 \delta
$$

According to the formula 6, the power angle characteristics of pumped storage unit can be drawed, as shown in fig. 2 .

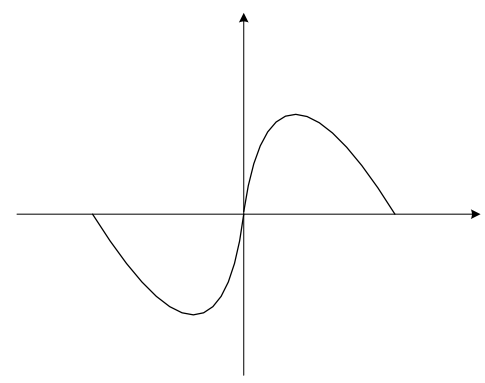

Fig.2 The diagram of power angle characteristics

The fig.2 shows that the pumped storage units will be operated under the condition of generator if $0^{\circ} \leq \delta \leq 180^{\circ}$ and when $-180^{\circ} \leq \delta \leq 0^{\circ}$, the pumped storage units are operated under the condition of motor.

\section{The Parameters of pumped storage units and situation of field test}

The capacity of pumped storage power station is $4 \times 300 \mathrm{MW}$, the main technical parameters are shown in table1 and table2.

Table 1 The main technical parameters of generator/motor

\begin{tabular}{|c|r|c|c|c|c|}
\hline Name & $\mathrm{U}_{\mathrm{N}} / \mathrm{kV}$ & $\mathrm{I}_{\mathrm{N}} / \mathrm{A}$ & $\cos \varphi$ & $\mathrm{U}_{\mathrm{LN}} / \mathrm{V}$ & $\mathrm{I}_{\mathrm{LN}} / \mathrm{A}$ \\
\hline Generator/ & 18 & $\begin{array}{c}10691 / \\
10662\end{array}$ & $\begin{array}{c}0.9 / \\
0.975\end{array}$ & 268 & 2060 \\
\hline
\end{tabular}

Table 2 The main technical parameters of transfomer

\begin{tabular}{|c|c|c|c|c|c|}
\hline Name & Type & $\begin{array}{c}\text { rated } \\
\text { transformation } \\
\text { ratio } / \mathrm{kV}\end{array}$ & $\begin{array}{c}\text { Transformer } \\
\text { tap }\end{array}$ & $\begin{array}{c}\text { actually } \\
\text { Transformation } \\
\text { ratio } / \mathrm{kV}\end{array}$ & S/MVA \\
\hline transformer & SSP-360000/500 & $515 \pm 2 \times 2.5 \% / 18$ & 3 & $515 / 18$ & 360 \\
\hline
\end{tabular}

There are 3 pumped storage units are operated under pumping condition at the same time in the field test, auxiliary power maintains normal operation mode and automatic excitation runs stably. Gradually increasing the excitation current,the output of reactive power will be risen.It is needed to record the initial operating parameters when the reactive power $\mathrm{Q}=0 \mathrm{MVar}$, which is shown in table3.

Table 3 The field test data of pumped storage units

\begin{tabular}{|c|c|c|c|c|c|c|c|}
\hline $\begin{array}{c}\text { Serial } \\
\text { number }\end{array}$ & $\begin{array}{c}\mathrm{P}_{\mathrm{G}} \\
/ \mathrm{MW}\end{array}$ & $\begin{array}{c}\mathrm{Q}_{\mathrm{G}} \\
/ \mathrm{MVar}\end{array}$ & $\begin{array}{c}\mathrm{U}_{\mathrm{S}} \\
/ \mathrm{kV}\end{array}$ & $\begin{array}{c}\mathrm{U}_{\mathrm{G}} \\
/ \mathrm{kV}\end{array}$ & $\begin{array}{c}\mathrm{I}_{\mathrm{G}} \\
/ \mathrm{kA}\end{array}$ & $\begin{array}{c}\mathrm{U}_{\mathrm{L}} \\
/ \mathrm{V}\end{array}$ & $\begin{array}{c}\mathrm{I}_{\mathrm{L}} \\
/ \mathrm{A}\end{array}$ \\
\hline 1 & 900 & 0.3 & 515.4 & 17.19 & 10.47 & 150.2 & 1487 \\
\hline 2 & 900 & 21.9 & 516.5 & 17.45 & 10.30 & 159.0 & 1589 \\
\hline 3 & 900 & 38.5 & 516.7 & 17.59 & 10.23 & 170.2 & 1656 \\
\hline 4 & 900 & 58.9 & 517.9 & 17.80 & 10.20 & 181.0 & 1769 \\
\hline 5 & 900 & 70.0 & 518.3 & 18.08 & 10.18 & 185.0 & 1796 \\
\hline
\end{tabular}

During the field test, the voltage varies with the reactive power changing which is shown in fig.3 and fig.4. 


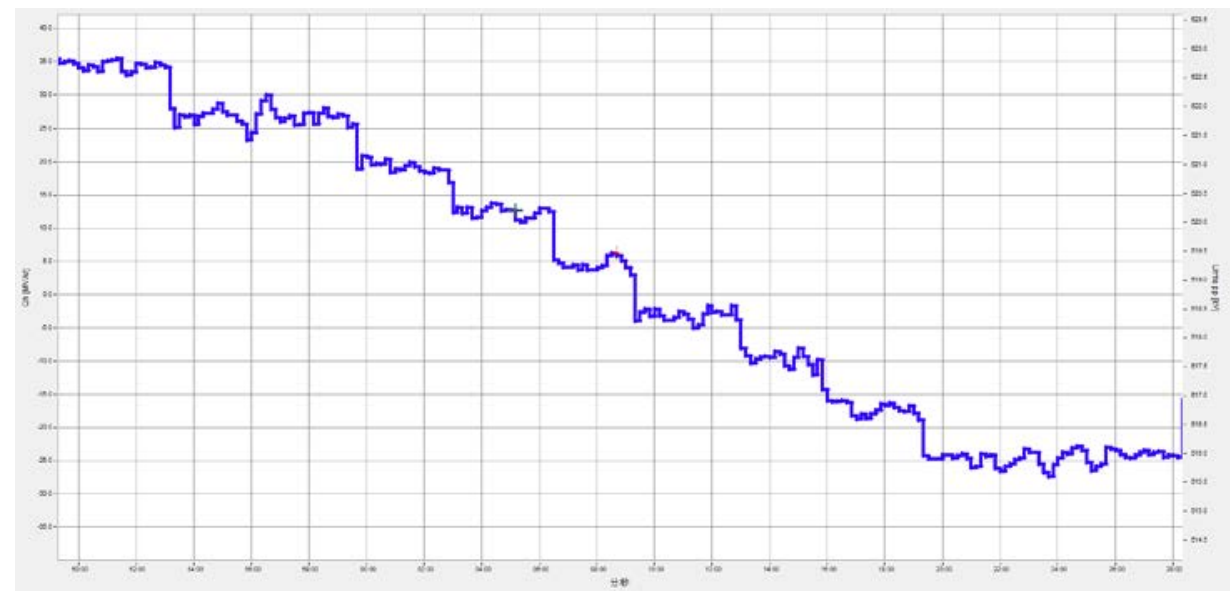

Fig.3 the voltage change curve when reactive power drops

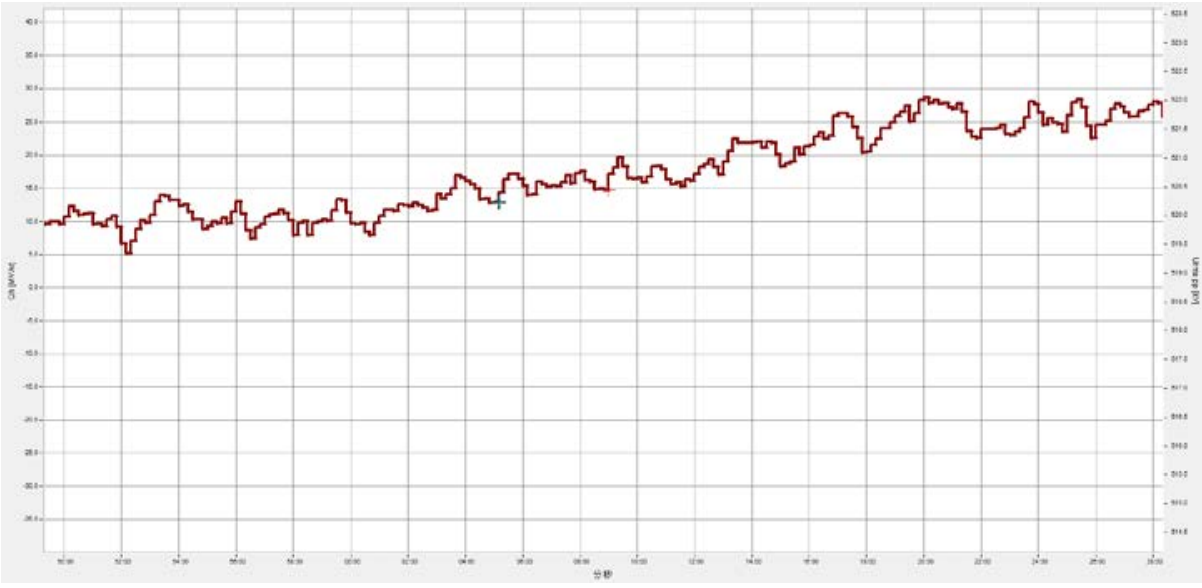

Fig.4 the voltage change curve when reactive power rises

The voltage harmonics produced in the field test are shown in Figure 5.

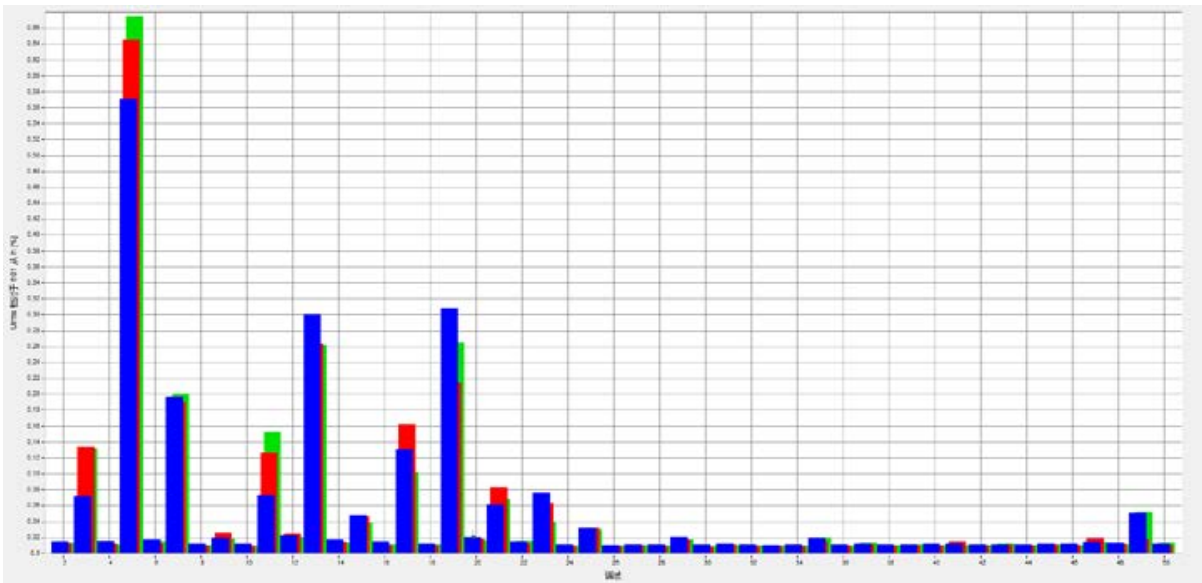

Fig.5 the column of voltage harmonics

\section{Conclusions}

This paper illustrates that the pumped storage units can be operated under the condition of generator and motor.The pumped storage unit consumes a large amount of reactive power when it is operated under the pumping condition, which will lead to the dorp of power system voltage.So the wind power will be abandoned if the pumped storage unit can not be operated under the pumping condition,which will effects the peak load regulation of power system. The reactive power can be produced by the pumped storage unit under the pumping condition, which will raise the system voltage. Therefore, the conclusion of this paper has guiding significance for the operation of 
pumped storage unit.

\section{References}

[1] Huang Chunhua. Operation of large synchronous generator [M]. Beijing: hydraulic and electric power press, 1992.

[2] Gao Zhihua,Ren Zhen,Huang Wen ying.Peak rgulation right and the corresponding transaction mechanism in electricity market[J].Proceedings of the C.SEE,2005,25(5);88-92.

[3] Qiu Wenqian.Operation optimization models for pumped storage power stations of daily and weekly regulation model[J].Hydropower Automation and Dam Monitoring,2004,28(5):51-54.

[4] Yu Xinmei,Xiong Xinyin,Wu Yaowu.Discussion on optimal model for peaking units'expansion planing and its appcation[J].Electric Power,2003,38(1):48-51.

[5] Yu Wenge.Operation modes of pumped storage power plant and the economic benefit analysis of power network[J].Water Power,2002(4):57-63.

[6] Xu Deqian ,Han Zhigang,Zhai Guoshou.Research on the optimal cooperation pattern of a pumped storage station with thermal power plants[J].Journal of Hydroelectric Enginering, 1996(4): 11-20.

[7] Luo Sha.Management Investigation and Benefit Evaluation for Pump Storage Station in U.S.[J].Electric Power,1997,7(30):55—58.

[8] Cao Fang, Zhang Lizi.Peak Load Regulation Analysis and Benefit Evaluation about Pumped Storage Plant[J].Modem Electric Power,2005,22(4):25—28. 